Gestão e Desenvolvimento, 22 (2014), 165-190

\title{
A AVALIAÇÃO DE DESEMPENHO DOCENTE NA PERSPETIVA DOS DIRETORES ESCOLARES: UM ESTUDO EMPÍRICO
}

\author{
Maria Helena Gonçalves* \\ Nuno Filipe Melão ${ }^{\dagger}$
}

\begin{abstract}
Resumo: A avaliação de desempenho docente é, na atualidade, amplamente encarada como uma estratégia que promove a eficácia dos sistemas de ensino. No entanto, a implementação de modelos avaliativos que visam conciliar o desenvolvimento profissional dos professores e a melhoria e qualidade das aprendizagens dos alunos tem gerado debate em torno dos propósitos e dispositivos legais da avaliação de desempenho. Neste contexto, importa conhecer a perspetiva dos diretores de escolas relativamente à avaliação de desempenho, já que sobre eles recai uma responsabilidade especial no processo. $O$ objetivo deste estudo é o de compreender as perceções dos diretores de escolas sobre a avaliação de desempenho docente bem como o modelo de avaliação implementado pelo D.R. $n^{\circ}$ 2/2010. O estudo é de natureza qualitativa e baseia-se em entrevistas semiestruturadas com doze diretores de escolas. Concluise que os diretores reconhecem a importância da avaliação de desempenho e têm expectativas positivas acerca dos seus efeitos. Contudo, na sua perspetiva, o modelo de avaliação do D.R. n. $^{o}$ 2/2010 não satisfez essas expectativas.
\end{abstract}

Palavras-chave: Avaliação de desempenho docente, diretores escolares, administração escolar

\footnotetext{
* Mestre em Ciências de Educação (Administração e Organização Escolar) pelo Centro Regional das Beiras, Universidade Católica Portuguesa.

$\dagger$ Professor auxiliar do Centro Regional das Beiras, investigador do CEGE, Universidade Católica Portuguesa. E-mail: nmelao@crb.ucp.pt
} 


\title{
EVALUATION OF TEACHERS PERFORMANCE IN THE PERSPECTIVE OF SCHOOL DIRECTORS: AN EMPIRICAL STUDY
}

\begin{abstract}
The teacher performance evaluation is, at present, widely seen as a strategy that promotes the efficacy of education systems. However, the implementation of evaluation models aiming at reconciling the professional development of teachers and the improvement and quality of student learning has generated debate about the purposes and legal provisions of performance evaluation. In this context, it is important to know the perspective of school principals regarding performance evaluation, since they have a special responsibility in the process. The aim of this study is to understand the perceptions of schools principals about teacher performance evaluation as well as the evaluation model implemented by the D.R. n. ${ }^{\circ}$ 2/2010. The study is qualitative in nature and is based on semi-structured interviews with twelve school principals. It is concluded that school principals recognize the importance of performance evaluation and have positive expectations about its effects. However, in their perspective, the evaluation model of the D.R. . $^{\circ}$ 2/2010 did not meet those expectations.
\end{abstract}

Keywords: Teacher performance evaluation, school principals, school administration

\section{INTRODUÇÃO}

Em educação, a preocupação fundamental é a aprendizagem dos alunos e, partindo deste pressuposto, a avaliação dessas aprendizagens tornou-se o principal critério de medição da eficácia dos sistemas de ensino. Consequentemente, a confrontação com o fraco desempenho dos alunos levou ao questionamento do trabalho das escolas, focalizando-se a atenção, na atualidade, na classe docente e na qualidade das suas práticas (Avalos, 2010).

Com efeito, depois de terem sido garantidos, na generalidade dos países, melhores recursos educativos, incluindo-se nestes Portugal, que fez um crescente e notório investimento em educação (Azevedo, 2002), a questão que se coloca diz respeito às razões pelas quais esse investimento não tem tido o correspondente retorno em termos de desempenho dos alunos, aumentando a pressão para que todos possam obter sucesso educativo, já que este é cada vez mais sinónimo de exclusão ou acesso ao sucesso na sociedade de conhecimento (Roldão, 1999).

Nesse sentido, a constatação de que "um dos pilares fundamentais de qualquer sistema de qualidade é a avaliação" (Vicente, 2004, p.154) fez 
com que desde os anos oitenta tenham vindo a ser implementados mecanismos avaliativos como incentivo às boas práticas e à qualidade da educação. Deste modo, o Estado-avaliador tornou-se um dos grandes trunfos das políticas educativas atuais na luta pela eficácia dos sistemas de ensino (Costa, 2007).

Neste contexto, perante a comprovação empírica de que os professores são a variável que na escola mais influencia o desempenho dos alunos (Goldrick, 2002), aborda-se a avaliação de desempenho docente enquanto estratégia de "mobilização e motivação dos professores para melhorarem a sua acção profissional, promovendo, simultaneamente, o seu desenvolvimento profissional e a aquisição de competências e melhorando o seu ensino e a aprendizagem dos alunos" (Moreira, 2009, p.39).

Ciente da importância da avaliação de desempenho enquanto mecanismo de desenvolvimento profissional dos professores e da importância destes "para os objetivos de melhoria das aprendizagens dos alunos" (Machado \& Formosinho, 2009, p.294), o sistema de ensino português, pela publicação do D.R. n. ${ }^{\circ} 2 / 2008$, de 10 de janeiro, e D.R. n. ${ }^{\circ}$ 2/2010, de 23 de junho, implementou nos ciclos avaliativos 2007/2009 e 2009/2011 modelos de avaliação de desempenho docente significativamente diferentes do modelo vigente durante 20 anos, com um formato claramente contextualizado pelas políticas educativas internacionais, pelos fenómenos de globalização e pela investigação educacional.

Até 2008, a avaliação de desempenho mereceu pouco relevo por parte da investigação educacional em Portugal e após essa data, momento da implementação do novo modelo de avaliação, tem-se vindo a assistir a um acréscimo de abordagens ao tema, da responsabilidade de investigadores e professores (e.g., Cardoso, 2012; Flores, Alves \& Machado, 2011; Formosinho, Machado \& Formosinho, 2010). Pretende-se com este trabalho contribuir para o aprofundamento sobre o tema dando voz a um grupo específico que tem a responsabilidade de aplicar nas escolas os modelos avaliativos - os diretores escolares - e cuja perspetiva tem sido um pouco descorada.

O estudo realizado propõe, assim, uma abordagem ao fenómeno da avaliação de desempenho, sendo que o objetivo é compreender que importância tem para os diretores das escolas a avaliação de desempenho docente e, à luz desse posicionamento, compreender como interpretam o modelo de avaliação instituído pelo D.R. n. ${ }^{\circ}$ 2/2010, em vigor em 2009/2011. 


\section{ENQUADRAMENTO TEÓRICO}

\subsection{Finalidades da Avaliação de Desempenho}

A avaliação de professores justifica-se pelas consequências que dela podem advir em termos de melhoria das práticas docentes e de melhoria das aprendizagens dos alunos. $\mathrm{O}$ inerente processo de questionamento da atuação do professor e de reflexão sobre como fazer para que os alunos aprendam mais (Assaél \& Pavez, 2008), induz a definição de objetivos estratégicos para que, a partir do desenvolvimento profissional, pelo melhoramento dos métodos de trabalho, seja salvaguardado o direito a aprender de todos os alunos, sinónimo de qualidade e equidade em educação (Murillo, 2007). Significa isto que a importância da avaliação de desempenho está ancorada nos seus distintos propósitos, aos quais estão subjacentes diferentes destinatários e diferentes usos sociais (Day, 2010; Flores, 2009).

A análise desses propósitos permite concluir que estes se fundem em duas categorias essenciais: a responsabilidade, com vista à prestação de contas, e o desenvolvimento profissional dos professores. A prestação de contas pela responsabilização pelo desempenho profissional, refletida na obrigatoriedade de apresentação de objetivos e resultados e na tomada de decisões relativas à gestão da carreira. $\mathrm{O}$ desenvolvimento profissional obtido pela mobilização da dimensão formativa da avaliação, o que implica a análise e reflexão sobre as práticas de ensino e a sua consequente mudança e melhoria (Stronge, 2010; Tardif \& Faucher, 2010).

Destes propósitos, emerge a finalidade de melhoria do desempenho da escola, inevitavelmente associada à qualidade do ensino (Bolívar, 2007) estando esta, por sua vez, associada a melhores aprendizagens, por parte dos alunos, espelhadas na melhoria dos seus resultados escolares (Bolívar, 2007; Moreira, 2009).

Esta relação linear e causal dos propósitos da avaliação assenta numa visão idealista dos efeitos e consequências da avaliação de desempenho, que vê nos professores um recurso crucial para a melhoria, sendo crescente a ideia de que a qualidade do processo educativo está claramente associada à qualidade dos professores (Nevo, 2005).

Assim sendo, torna-se evidente que à avaliação de desempenho importa a melhoria do desempenho coletivo dos professores (Stronge, 2010), pois só o conjunto de professores poderá melhorar a qualidade das práticas de ensino, nas escolas. 


\subsection{As Funções da Avaliação de Desempenho}

$\mathrm{Na}$ atividade avaliativa coexistem a função formativa e sumativa. Embora Scriven (1997) afirme que não há funções certas ou erradas, a função formativa será a mais importante para os docentes, na medida em que se destina a favorecer o seu crescimento profissional. Ao "fazer das práticas docentes lugares estratégicos de investigação" (Morgado, 2005, p.46), pretende-se que o professor se assuma como um sujeito ativo que identifica, na avaliação, oportunidades de desenvolvimento e aperfeiçoamento da prática profissional (Danielson, 2010; Fernandes, 2009), muito para além da certificação e reconhecimento da competência mínima para a docência. Trata-se de um processo que visa aprofundar o conhecimento dos pontos fortes, bem como as áreas carentes de formação produzindo informação qualitativa essencial à orientação e regulação da ação e à elaboração de planos de melhoria profissional (Ruivo \& Trigueiros, 2009).

Os professores percecionam a função sumativa da avaliação como um mecanismo de controlo e de responsabilização, que poderá ser usado contra si próprios (Campos, 2005). Expressões como desempenho de mérito, o destaque dado ao que funcionou mal, a comparação com os outros e a interferência com a progressão na carreira, justificam os medos e inseguranças provocados pela avaliação (Clímaco, 2007). Para esta inquietação, contribui o facto de os professores, enquanto avaliadores, serem conhecedores do poder da função sumativa da avaliação e do efeito punitivo ou compensador que esta tem nas classificações dos seus alunos (Mestre, 2002).

$\mathrm{Se}$ a isto se acrescentar a inexistência de dados objetivos sobre o impacto efetivo da atuação do professor no desempenho dos alunos (Abrantes, 2010; Avalos, 2010), a par da consciencialização de que para o sucesso educativo dos mesmos, concorre o contexto socioeconómico das famílias, o investimento público em educação, a diferenciação precoce dos percursos formativos, o grau de desenvolvimento do país e a capacidade da escola, no exercício da sua autonomia, de desenvolver medidas organizativas e pedagógicas adequadas, e ainda que testes estandardizados avaliam as aprendizagens cognitivas, mas não avaliam todas as dimensões do trabalho docente (Abrantes, 2010), afiguram-se legítimas as cautelas e oposição dos professores, como refere Campos (2005), à função sumativa da avaliação de desempenho.

A avaliação com objetivos sumativos fez soar outros alertas. A implementação de um sistema de avaliação orientado para o 
reconhecimento do mérito poderá levar à disputa pelas melhores classificações, pondo em causa o trabalho colegial, nuns casos, e/ou agravar a situação de isolamento profissional e de individualismo de alguns professores, noutros (Bolívar, 2007; Lima, 2002).

Em todo o caso, a afirmação de que "a investigação e prática recentes estão a manifestar a necessidade de pressão externa para que ocorra melhoria" (Bolívar, 2007, p.9), permite um outro olhar sobre a função sumativa se se encarar a responsabilização pelos resultados como uma oportunidade de desenvolvimento. Com efeito, a confrontação e a mediatização dos resultados académicos dos alunos levou a sociedade a questionar os resultados da escola e sobre ela exercido uma pressão externa que poderá obrigá-la a mobilizar-se na procura de estratégias de melhoria.

Neste seguimento, tem vindo a ser debatida a questão da complementaridade ou antagonismo das duas funções, pois a forma como se aborda esta questão, bem como o modelo de avaliação adotado, podem permitir ou não concretizar os objetivos da avaliação de desempenho docente.

$\mathrm{Na}$ atualidade, afigura-se como tendência de alguns sistemas de ensino (OCDE, 2009) a realização de um "esforço concertado para estabelecer uma ligação lógica entre os dois propósitos" (Stronge, 2010, p.27). Esta tendência é justificada pela vontade de se avaliar os resultados e os processos que estiveram na base desses resultados, numa tentativa de conciliação entre predisposição para a melhoria e o desenvolvimento contínuo do professor associado ao controle da eficácia do seu desempenho e à sua progressão na carreira (Flores, 2009).

\subsection{A Competência dos Avaliadores}

Ser competente profissionalmente é estar capacitado para assumir determinadas responsabilidades, sendo que, em avaliação, esta competência resulta da conjugação de três requisitos: a experiência no ensino, a formação especializada e o treino (Moreira, 2011; Ruivo \& Trigueiros, 2009). Resulta ainda da dimensão pessoal que exige um indivíduo sensível, com capacidade analítica e de comunicação empática e elevada responsabilidade social, capaz de olhar o avaliado sob vários prismas (Ruivo \& Trigueiros, 2009). Se uma das dimensões fornece o conhecimento que leva à apropriação da técnica destinada à "medição" dos desempenhos, a outra fornece a capacidade de ver para além da técnica e que permite medir e "lidar com o não classificável" (Silva, 2011, p.121). 


\subsection{Periodicidade da Avaliação de Desempenho}

A investigação defende que a frequência da avaliação de desempenho está dependente dos seus propósitos, recomendando um período de três anos para o período formativo e um de um ano para o período sumativo (Moreira, 2011). Estes seriam os espaços de tempo considerados necessários para que, a partir de processos de prestação de contas do trabalho desenvolvido, se estruture o desempenho numa perspetiva desenvolvimentista e de gestão da carreira.

Simões (2000) refere a necessidade de adequação da periodicidade à situação profissional dos professores, recomendando para os professores experientes, um espaço temporal de três ou quatro anos e uma periodicidade mais curta para os professores iniciantes.

\subsection{A Avaliação de Desempenho e a Responsabilização pelos Resultados dos Alunos}

Ao estado-avaliador interessam mais os resultados ou produtos da educação do que os processos e escudado na ideia de que "a qualidade de ensino de um professor é tanto maior quanto mais elevadas são as performances dos respectivos alunos" (De Ketele, 2010, p.20), insiste em fazer recair sobre a escola e, cada vez mais, sobre os professores a responsabilidade do sucesso escolar, legitimando, assim, a prestação de contas, numa lógica de responsabilização pelas aprendizagens dos alunos.

Ora, citando Góis e Gonçalves (2005, p.11), "nem todos os resultados escolares são mensuráveis através de exames", como também nem todas as aprendizagens são igualmente relevantes para o bom desempenho em exames.

Assim, avaliar a eficácia do professor pelos resultados de avaliações externas, que são "razoavelmente fiáveis para avaliar fragmentos de informação, conhecimento de baixo nível e procedimentos de rotina, mas são insatisfatórios para avaliar a compreensão conceptual" (Danielson, 2010 , p.20) significa obter uma visão fragmentada das aprendizagens e competências dos alunos (Murillo, 2007).

Para esta situação contribui a extrema dificuldade em conseguir isolar a mais-valia que cada professor, por si, representa para esses resultados, para além da incapacidade de medir o que faz o professor para além da sala de aula, como se envolve e executa as atividades, e pela dificuldade em definir o que é um professor competente, do ponto de vista dos destinatários da sua ação (Roman \& Murillo, 2008). 
Além disso, a insistência nas aprendizagens que satisfaçam indicadores de desempenho gratos ao estado-avaliador que poderá levar ao empobrecimento do processo didático e a um menor investimento no desenvolvimento de competências sociais, importantes ao desenvolvimento integral de cada aluno, é outro risco a ter em conta (Roldão, 2003; Díaz, 2003).

Há também que ter que ter em linha de conta o fator aluno, que introduz uma inevitável margem de incerteza resultante da sua predisposição e vontade em aprender, da responsabilização pelo trabalho que desenvolve e do modo como se envolve na interação com os professores (Danielson, 2010). Assim, na demanda por melhores níveis de aprendizagens por parte de uma população escolar heterogénea, não é suficiente o professor ensinar, mas é também absolutamente necessário que o aluno estude e aprenda (Campos, 2005).

\subsection{O Modelo de Avaliação Instituído pelo D.R. n. ${ }^{\circ}$ 2/2010}

Em conformidade com a tendência crescente de se encarar as funções formativa e sumativa "preferencialmente, de forma complementar e sistémica" (Ramos, 2007, p.11), o modelo de avaliação instituído pelo D.R. n. ${ }^{\circ} 2 / 2010$, de 23 de junho, reafirmou o propósito de desenvolvimento profissional, dando destaque à função formativa da avaliação e paralelamente associou-lhe mecanismos de reconhecimento do mérito do desempenho e a estes, a progressão na carreira.

Da análise efetuada ao modelo em estudo resultou um quadro resumo (cf. Tabela 1), cuja estrutura foi reproduzida do esquema elaborado por Flores (2010) relativo ao modelo legislado pelo D.R. n. ${ }^{\circ}$ 2/2008, de 10 de janeiro.

Do exposto, salientamos, o facto do modelo de avaliação ter recorrido às técnicas de observação de aula, de auto-avaliação, de avaliação pelos pares, e ainda à entrevista (quando requerida pelo avaliado). Esta é a opção mais indicada por permitir a triangulação de fontes e dados, condição essencial para aumentar o grau de validade da avaliação e proporcionar "uma visão mais completa e justa do desempenho" (Stronge, 2010, p.35).

A observação de aulas, ao proporcionar um suporte real para a reflexão sobre a ação, faz emergir contextos potencialmente muito formativos, tornando-se particularmente adequada aos propósitos de melhoria do rendimento individual, do rendimento coletivo dos professores e da melhoria da qualidade das aprendizagens. É ainda um contributo para a avaliação de desempenho, enquanto mecanismo de prestação de contas, 
pois a abertura da sala de aula aos olhares e reflexão de outros e a inerente explicação do que se fez e porque se fez, acarreta consigo um "maior conhecimento do ato educativo" (Cruz, 2011, p.86), conferindo transparência ao processo de ensino-aprendizagem.

\section{Tabela 1}

Modelo de avaliação do D.R. n. ${ }^{\circ}$ 2/2010, de 23 de junho

\begin{tabular}{|c|c|}
\hline Periodicidade & - De dois em dois anos \\
\hline Principais efeitos & - Progressão na carreira \\
\hline $\begin{array}{l}\text { Elementos de } \\
\text { referência }\end{array}$ & $\begin{array}{l}\text { - Padrões de desempenho docente estabelecidos a nível } \\
\text { nacional } \\
\text { - Objetivos e metas do Projeto Educativo e Plano Anual e } \\
\text { Plurianual de Atividades } \\
\text { - Objetivos individuais facultativos }\end{array}$ \\
\hline Avaliadores & $\begin{array}{l}\text { - Relatores } \\
\text { - Coordenador de departamento curricular (avaliam os } \\
\text { relatores e os professores com posicionamento mais elevado } \\
\text { na carreira) } \\
\text { - Professores (avaliam o coordenador de departamento com } \\
\text { uma ponderação máxima de 10\%) } \\
\text { - Júri de avaliação } \\
\text { - Diretores/presidentes de CAP (avaliam os elementos da } \\
\text { direção, os coordenadores de departamento e de } \\
\text { estabelecimento) } \\
\text { - Diretor Regional de educação (avalia os diretores) }\end{array}$ \\
\hline Aspetos a avaliar & $\begin{array}{l}\text { - Relator pondera as dimensões do desempenho docente, } \\
\text { nomeadamente: } \\
\text { - Vertente profissional, social e ética que inclui o compromisso } \\
\text { com a construção do desenvolvimento profissional; o } \\
\text { compromisso com a construção da aprendizagem e do } \\
\text { desenvolvimento pessoal e cívico dos alunos e o compromisso } \\
\text { com o grupo de pares e com a escola; } \\
\text { - Desenvolvimento do ensino e da aprendizagem que avalia } \\
\text { a preparação e organização das atividades letivas; a sua } \\
\text { realização; a relação pedagógica com os alunos e os } \\
\text { processos de avaliação das aprendizagens; } \\
\text { - Participação na escola e relação com a comunidade que } \\
\text { avalia o contributo para a concretização do Projeto } \\
\text { Educativo e do Plano Anual e Plurianual de Atividades; a } \\
\text { participação nas estruturas de coordenação educativa, } \\
\text { supervisão pedagógica e de administração e gestão; a } \\
\text { participação em projetos de investigação, desenvolvimento e } \\
\text { inovação educativa e sua correspondente avaliação; } \\
\text { - Desenvolvimento e formação profissional ao longo da vida } \\
\text { que avalia a formaça contínua realizada e o }\end{array}$ \\
\hline
\end{tabular}




\begin{tabular}{|c|c|}
\hline & desenvolvimento profissional. \\
\hline $\begin{array}{l}\text { Procedimentos e } \\
\text { instrumentos }\end{array}$ & $\begin{array}{l}\text { - Calendarização do processo a cargo do diretor da escola; } \\
\text { - Apresentação de objetivos individuais (facultativos), } \\
\text { correspondendo a uma proposta que permita aferir o } \\
\text { contributo do docente para os objetivos e metas da escola. } \\
\text { Recolha de dados através de instrumentos de registo } \\
\text { elaborados pela comissão de coordenação de avaliação de } \\
\text { desempenho e aprovados pelo conselho pedagógico, no } \\
\text { respeito pelos padrões de desempenho docente e pelas } \\
\text { orientações do Conselho Científico para a Avaliação de } \\
\text { Professores; } \\
\text { - Processo avaliativo integra as seguintes fases: observação de } \\
\text { aulas quando requerida e respetiva apreciação; elaboração } \\
\text { do relatório de autoavaliação; apreciação do relatório de } \\
\text { autoavaliação; realização de uma entrevista individual se } \\
\text { requerida pelo avaliado; apreciação pelo júri da ficha de } \\
\text { avaliação global; análise dos dados pelo júri; validação das } \\
\text { propostas das menções de muito bom, excelente e } \\
\text { insuficiente; comunicação, por escrito, ao avaliado, da sua } \\
\text { classificação e menção. }\end{array}$ \\
\hline $\begin{array}{l}\text { Classificação } \\
\text { final }\end{array}$ & $\begin{array}{l}\text { Excelente: 9-10; Muito bom: } 8 \text { - 8,9; Bom: 6,5-7,9 } \\
\text { Regular: } 5 \text { - 6,4; Insuficiente: } 1 \text { - 4,9 } \\
\text { - Existe um sistema de quotas por escola para as menções de } \\
\text { excelente e muito bom, fixadas em função dos resultados da } \\
\text { avaliação externa da escola. }\end{array}$ \\
\hline $\begin{array}{c}\text { Coordenação do } \\
\text { processo }\end{array}$ & $\begin{array}{l}\text { - A comissão de coordenação da avaliação de desempenho de } \\
\text { cada escola integra o presidente do conselho pedagógico e } \\
\text { quatro outros membros do conselho pedagógico, eleitos de } \\
\text { entre os respetivos membros. Compete a esta comissão } \\
\text { assegurar a aplicação objetiva e coerente do sistema de } \\
\text { avaliação tomando em consideração o PE e o PAA, as } \\
\text { especificidades de cada organização educativa e as } \\
\text { orientações do conselho científico; transmitir a todos os } \\
\text { relatores as orientações adequadas e validar as } \\
\text { classificações finais. }\end{array}$ \\
\hline
\end{tabular}

A autoavaliação, igualmente importante, representa o momento em que o avaliado se confronta consigo, com as suas potencialidades mas também com os pontos fracos, tornando-se um agente ativo no processo avaliativo e coautor do julgamento relativo ao seu desempenho (Caetano, 2008). Contudo, se, por um lado, esta técnica pode evitar controvérsia, porque é o avaliado que fala de si, fazendo-o com profundo conhecimento de causa, por outro, existe o risco de cair no auto enaltecimento e inflacionando as classificações. Por conseguinte, tendencialmente, a autoavaliação manifesta mais leniência, menos validade discriminante e menos fidelidade do que as avaliações realizadas por outros avaliadores (Chiavenato, 1990). 
Quanto à avaliação por pares, é notório que estes estão muito bem posicionados para avaliar o trabalho dos colegas, em virtude de estarem familiarizados com todo o processo educativo e com as exigências com que se confrontam os professores (Peterson, 1997). Com efeito, a avaliação por pares permite apreciar a atuação do professor nos diferentes aspetos inerentes à multidimensionalidade da profissão docente, favorecendo a construção de uma imagem a mais completa possível do desempenho do avaliado.

Afiguram-se, porém, alguns constrangimentos. A apologia do trabalho colegial em rede, em que muito do trabalho desenvolvido é de responsabilidade partilhada, abre caminho a questões éticas, levando a que nem todos encaram como pacífico que alguns professores passem a ser avaliadores do desempenho de outros. Enquanto algumas vozes consideram que avaliar o trabalho no qual se está envolvido, dificulta e condiciona a função dos avaliadores (Tardif \& Faucher, 2010), outras alertam para a possibilidade de, face ao caráter sumativo da avaliação, os docentes adotarem uma postura competitiva, refugiando-se num trabalho mais individualizado, perpetuando uma postura de isolamento e individualismo (Lima, 2002; Bolívar, 2007).

Acrescem ainda sérios riscos de as relações pessoais entre avaliadores e avaliados poderem interferir também na avaliação de desempenho, com dois sentidos distintos: umas vezes, são as relações interpessoais que poderão interferir na classificação; outras vezes, são as classificações atribuídas que poderão interferir nas relações interpessoais. Daqui decorre que o erro de leniência é um dos principais constrangimentos à utilização deste tipo de fonte.

O D. R. n. ${ }^{\circ} 2 / 2010$, de 23 de junho, designa os pares para avaliadores do desempenho docente, respeitando uma espécie de hierarquia interna, em resultado da designação para determinadas funções. $\mathrm{O}$ diretor avalia os subdiretores e adjuntos, os coordenadores de departamento e de estabelecimento. Os coordenadores de departamento, por sua vez, avaliam os relatores por si nomeados para serem avaliadores dos restantes professores.

O grosso dos avaliadores é composto pelo grupo dos relatores e estes integram a comissão de coordenação da avaliação, a quem compete atribuir a classificação final ao docente. O relator é, em regra, um professor da escola designado segundo os critérios: grupo de recrutamento, posicionamento na carreira e grau académico igual ou superior ao avaliado, aos quais o legislador acrescentou a variável "sempre que possível". 
Deste modo, professores com um percurso profissional idêntico passaram a integrar dois grupos distintos: o grupo a quem é dado o poder de avaliar e o grupo objeto desse poder. A separá-los está uma questão de tempo de serviço que, muitas vezes, se traduz na diferença de um índice remuneratório. Trata-se de uma nomeação suportada em critérios administrativos, alheada da competência técnica e científica para o efeito.

Este poder de avaliar associado à ideia de que "a competência não é necessariamente proporcional aos anos de prática" (Cunha, 2008, p.84) levou a classe docente a questionar a legitimidade dos seus avaliadores. A contestação acentuou-se face à dificuldade de muitas escolas, designarem os avaliadores, no respeito pelo cumprimento dos critérios de designação inscritos no art. ${ }^{\circ} 13 .^{\circ}$ do D.R. n. ${ }^{\circ} 2 / 2010$ e nos números 4 e 5 do art. ${ }^{\circ} 35 .^{\circ}$ do D.L. n. ${ }^{\circ}$ 75/2010, de 23 de junho. Como solução, o ME autorizou um conjunto de medidas excecionais relativamente à designação dos avaliadores, tendo o grupo de recrutamento e a barreira dos $3 .^{\circ}$ e $4 .^{\circ}$ escalões deixado de ser constrangimentos.

Embora a opinião pública possa pensar que os professores estão à vontade no papel de avaliadores, por lidarem diariamente com práticas avaliativas e, embora nas escolas se oiça dizer que todos sabem identificar quais os colegas que gostariam de ter para professores dos seus filhos, a verdade é que nem avaliar as aprendizagens dos alunos é igual a avaliar o desempenho dos professores (CCAP, 2009), nem se avaliam as mesmas competências nos alunos e nos professores (Posada, 2009).

De qualquer modo, e independentemente da absoluta necessidade de que os avaliadores recebam formação adequada ao exercício da função, a ideia de que avaliar o desempenho é um processo difícil e muito técnico traz associada a si o pressuposto de que é uma atividade que deve ser realizada por avaliadores especialmente preparados para o efeito. E, munidos deste argumento, os professores poderão demarcar-se do poder de avaliar e "desapossessados da avaliação" (Alves \& Machado, 2008, p.53) remetem a responsabilidade para fora de si próprios (Figari, 2007).

A periodicidade do modelo objeto deste estudo é de dois anos, justificada pela necessidade de aproximação à periodicidade do SIADAP 3. Trata-se de um período de tempo que não permite melhorias significativas de um ciclo avaliativo para outro, tendo em conta que os professores precisam de tempo para se desenvolverem e que sem ele, a sua capacidade de aprendizagem fica limitada. Acresce que a responsabilização pelos resultados não deixa muito tempo útil para que o professor avaliado tire partido da função formativa da avaliação, nem que os avaliadores proporcionem o acompanhamento desejável a professores que denotem fragilidades. 


\section{METODOLOGIA}

Importa pois que a avaliação de desempenho se torne um empreendimento realmente significativo e útil (Stronge, 2010) para os professores e para os alunos. Cientes desta necessidade, realizou-se um estudo cujo objetivo consistiu em perceber que importância tem para os diretores de escolas, a avaliação de desempenho docente e, à luz desse posicionamento, perceber como interpretam o modelo de avaliação em vigor no ciclo 2009/2011. Considera-se pertinente este objetivo na medida em que os resultados deste estudo poderão de algum modo contribuir para a tomada de opções relativamente à construção de modelos avaliativos mais próximos dos intervenientes no processo.

Dado ser propósito desta investigação compreender as opiniões e considerações pessoais dos diretores relativamente à avaliação de desempenho, interessando portanto que os sujeitos dessem a conhecer o seu ponto de vista, optou-se pela investigação qualitativa.

\subsection{Técnica de Recolha da Informação}

Nesse seguimento, selecionou-se a entrevista semiestruturada como técnica de recolha da informação. Subjazem a esta opção, o facto de a entrevista ser considerada um dos processos mais diretos de encontrar informação sobre um determinado fenómeno (Tuckman, 2000) e, sendo semiestruturada por permitir a exploração de um conjunto de questões temáticas visando suscitar "respostas amplas e desejavelmente longas eivadas de pormenores" (Máximo-Esteves, 2008, p.96) com a garantia de, no final, se "obter dados comparáveis entre os vários sujeitos" (Bodgan \& Biklen, 1994, p.135).

\subsection{Participantes no Estudo}

$\mathrm{Na}$ identificação da amostra, recorreu-se à amostragem por conveniência conjugada com a técnica da amostragem de casos típicos. Assim, e considerando que "a investigação qualitativa focaliza-se em amostras relativamente pequenas, ou mesmo casos únicos, seleccionados intencionalmente" (Carmo \& Ferreira, 2008, p.209) e ainda o facto de os informadores qualificados serem diretores de escolas, que aplicaram o modelo de avaliação de desempenho em estudo, variável nada significativa em termos de heterogeneidade da população, considerou-se não ser necessário adotar cuidados especiais relativamente à diversidade de perfis 
entre os diretores de escola. Estabeleceu-se uma amostra de doze entrevistados, pertencendo todos à direção de estabelecimentos de ensino do distrito de Viseu. A amostra é constituída por dois diretores de escolas secundárias ( $3 .^{\circ}$ ciclo e ensino secundário), dois diretores de agrupamentos de escolas (do pré-escolar ao $12 .^{\circ}$ ano), sete diretores de agrupamentos de escolas (do pré-escolar ao $9 .^{\circ}$ ano) e um diretor (do pré-escolar ao $6 .^{\circ}$ ano).

Os diretores participantes foram convidados a colaborar, tendo dado autorização para a gravação das entrevistas que se realizaram nas escolas, e que foram, posteriormente, transcritas na íntegra.

\subsection{Técnica de Análise dos Dados}

A técnica de análise de conteúdo afigurou-se como uma consequência lógica da aplicação da técnica da entrevista, já que na essência produz conhecimento pela interpretação do significado implícito nos dados recolhidos. Tal facto exigiu uma dupla compreensão da mensagem, pois pretendia-se não só "compreender o sentido da comunicação mas também e, principalmente, desviar o olhar para uma outra significação, uma outra mensagem entrevista através ou ao lado da mensagem primeira" (Bardin, 2008, p.41).

Realizou-se uma leitura flutuante com vista ao primeiro contacto com os dados a explorar. Os dados brutos foram depois agregados em unidades de registo e de contexto, regra geral, por palavra ou tema, equivalendo a unidades de significação e que permitiram uma descrição exata das características pertinentes do conteúdo (Bardin, 2008).

À partida, dispunha-se de um conjunto de categorias formuladas com base nos objetivos do estudo e nas questões constantes da entrevista. No entanto, deixámos que outras categorias emergissem dos dados, por se entender que tal opção facilitaria a fidelidade ao pensamento dos entrevistados (Esteves, 2006). O percurso foi sedimentado na expressão: "caminha-se dos dados empíricos para a formulação de uma classificação que se lhes adeqúe" (Esteves, 2006, p.110).

\section{RESULTADOS}

\subsection{A Perspetiva dos Diretores sobre a Avaliação de Desempenho}

Relativamente à questão temática, o significado da avaliação de desempenho, foi possível aferir que a avaliação de desempenho é perspetivada pelos diretores como muito importante, na medida em que "é um momento de reflexão sobre o que cada um faz e ponto de partida para a 
mudança e melhoria das práticas docentes" (D6) e "pode ter contributos significativos para o desenvolvimento profissional do docente" (D8).

Coerentemente, os diretores consideram que a finalidade primeira da avaliação é o desenvolvimento profissional dos professores, a partir do qual se promove a qualidade do ensino e, por conseguinte, identificam os professores e os alunos como os principais e mais diretos destinatários dessa avaliação. No entanto, as famílias, o sistema de ensino e a administração central também dela beneficiam, visto o bom desempenho dos alunos agradar às famílias, sendo um bom indicador da eficácia dos professores, o que, acrescido da diferenciação dos desempenhos, agrada à administração central.

Um dos tópicos que obteve unanimidade de respostas foi a concordância relativamente à diferenciação do mérito do desempenho, por ser considerada um mecanismo impulsionador do desenvolvimento profissional: "Tem que haver diferenciação, porque se não houver diferenciação toda a gente é medida pela mesma bitola e portanto deixa de haver aqui desenvolvimento pessoal e profissional" (D11).

Os diretores frisaram que é a competência assente na demonstração de boas práticas que deve estar subjacente à diferenciação do desempenho, em vez da competência profissional assente no tempo de serviço, já que é do senso comum que nem todos os docentes com muitos anos de carreira são profissionais com elevado desempenho, pelo que "é importante haver um sistema que permita dizer que estes são melhores do que aqueles, mas são melhores,...porque há uma prática continuada e sistemática que prova à sociedade com que eu sou bom professor!" (D11).

Importa destacar que para dez dos doze participantes, o reconhecimento da excelência do desempenho implica a obrigatoriedade da avaliação da dimensão do desenvolvimento do ensino e da aprendizagem, em contexto de prática letiva, na esteira das atuais tendências avaliativas que reconhecem ser "difícil imaginar uma avaliação da profissionalidade docente que não incluísse sessões em sala de aula" (Tardif \& Faucher, 2010:49).

O facto da atividade letiva ser "a componente estruturante, digamos assim, de qualquer docente" (D7) motivou a afirmação por parte de alguns diretores de que todos os professores em avaliação devem ser sujeitos a momentos de supervisão em sala de aula, pelo valor instrumental que esta pode ter em prol do seu crescimento profissional contínuo (Machado, Alves \& Gonçalves, 2011): "Acho que todos devem ser submetidos a observação de aulas, independentemente das menções de muito bom e 
excelente... entendo que a observação de aulas contribui para o caráter formativo da avaliação" (D3).

Relativamente aos critérios de nomeação dos avaliadores, o critério administrativo de escalão da carreira, levou os diretores a posicionaram-se em dois grupos distintos: o que concorda com esse critério e o grupo que dele discorda. Enquanto uns afirmam que, em caso algum, deverá o avaliador estar num patamar inferior ao avaliado, já que "o ponto de referência é sempre aquele que tem mais experiência" (D6), e não seria aceitável que professores com menos tempo de serviço fossem avaliadores de professores mais antigos na carreira; outros consideram que um escalão acima não representa mais competência, atendendo a que a progressão na carreira tem ocorrido pela mera contagem do tempo de serviço, sendo mais importante que o avaliador seja "alguém reconhecido pelo seu avaliado, até porque o reconhecimento nem sempre tem a ver com um patamar mais acima" (D5), além de que a "partir de dez, quinze anos de experiência já não há tanta diferença" (D1).

Independentemente do ponto de vista relativamente aos critérios de nomeação, a competência profissional para o efeito foi entendida como essencial para a legitimidade e credibilidade dos avaliadores, à semelhança dos resultados obtidos no estudo de Cardoso (2012). Nesse contexto, por unanimidade, os diretores destacam como deveras importante, o critério da formação especializada em avaliação de desempenho.

É também opinião dos inquiridos que os avaliadores deverão ser sempre professores e do mesmo grupo de recrutamento dos avaliados, pelo facto de, na avaliação da dimensão do ensino e aprendizagem, ser importante conhecer a didática da disciplina/área do avaliado, para se aferir da pertinência e adequação das estratégias e metodologias adotadas.

Outra informação a reter é a posição dicotómica dos diretores respeitante à origem dos avaliadores, sendo, no entanto, mais significativo o grupo adepto dos avaliadores externos. Este considera que um avaliador exterior à escola do avaliado "permite uma observação mais limpa, longe das rotinas adquiridas e das proximidades positivas ou negativas" (D4), conferindo mais isenção e neutralidade ao processo, para além de resolver o problema ético de avaliar o desempenho de atividades às quais o avaliador não é de todo alheio.

Tendo em conta que os professores têm sido pouco recetivos a observações externas à escola (Ferreira, 2006), tudo indica que esta abertura ao exterior se justifica, sobretudo, pela não concordância do recurso a avaliadores internos devido às relações de proximidade entre pessoal docente avaliador e avaliado, tal como se depreende da seguinte observação: 
Avaliação entre pares é muito problemática porque, quer as pessoas queiram quer não, há uma proximidade muito grande e a proximidade não permite que as pessoas tenham a racionalidade e a clarividência de afastar o que é pessoal da profissão,... e começam as divergências e então o clima é terrível (D11).

Os diretores adeptos da avaliação por pares, são-no por considerarem que só assim se consegue fazer um acompanhamento efetivo do avaliado e construir uma imagem a mais aproximada possível do seu valor. É pertinente, aqui, destacar que os inquiridos julgam que a avaliação deve ser de responsabilidade partilhada - partilhada pelos avaliadores internos, nomeadamente o diretor, o conselho pedagógico e o próprio docente através da sua autoavaliação, e partilhada entre avaliadores internos e externos:

Partilhada. A participação na vida da escola pode e deve ser avaliada por quem está no terreno (os pares). A componente científica e didática deve ser da responsabilidade de alguém exterior (à escola) com formação apropriada, para garantia de rigor e isenção (D10).

Ainda relativamente às fontes de avaliação, os diretores percecionam as auto-avaliações como um campo propício ao enaltecimento pessoal, pelo que cientes que, muitas vezes, a auto-imagem não corresponde à héteroimagem, concordam que a auto-avaliação seja tida em conta na apreciação e classificação final, desde que o desempenho descrito seja fiel ao desempenho evidenciado. Contudo, fazem depender o peso a atribuir-lhe da apropriação que for feita do significado de auto-avaliação:

A auto-avaliação, tudo depende de como ela é feita... As pessoas fazem uma auto-avaliação mas nem têm bem a noção do que é fazer uma auto-avaliação ... A auto-avaliação tinha que ser: o que é que eu fiz, o que fiz bem, o que é que eu fiz mal e o que posso melhorar! E isso em geral não tem aparecido [...] Sendo assim, ela não tem qualquer significado. Agora se tiver o significado de ser um processo em que as pessoas refletem e depois apresentam estratégias para eles próprios melhorarem e para a melhoria do sistema, então ai tem todo o sentido (D1).

Assim, o grau de honestidade e o facto de a auto-avaliação poder ser "um fator indutor do desenvolvimento profissional" (Machado, Alves \& Gonçalves, 2011, p.10) que "mobiliza a reflexão como estratégia de ação" (Lima \& Moreira, 2011, p.108) determina, na perspetiva dos inquiridos, a possibilidade do avaliado ser coautor do julgamento relativo ao seu desempenho. 
Relativamente à periodicidade da avaliação de desempenho, $50 \%$ dos inquiridos apontou para períodos de 4 anos coincidentes com o tempo de permanência nos escalões da carreira. Os restantes $50 \%$ defenderam uma periodicidade mais curta como estratégia para manter acesa a pressão sobre os professores, e por permitir um feedback que visa obter efeitos imediatos, provocando uma melhoria rápida do desempenho do avaliado. Este enfoque na vertente formativa motivou uma opinião favorável à avaliação contínua por se entender que "a valorização não tem um período temporal delimitado" (D11) e uma outra favorável à existência de um modelo cuja periodicidade fosse estabelecida pelo "próprio docente quando sentisse necessidade de ser avaliado" (D7).

\subsection{A Perspetiva dos Diretores sobre o Modelo de Avaliação}

Quanto à questão temática, o modelo de avaliação do D.R. n. 2/2010, a apreciação dos diretores é bastante negativa. Em nenhuma das entrevistas foi encontrada uma resposta satisfatória relativamente ao facto do modelo de avaliação ter conseguido atingir os objetivos que se propunha e, nessa lógica, nem trouxe melhorias às práticas docentes, nem trouxe benefícios ao processo ensino-aprendizagem, nem melhorou os resultados dos alunos e também não conseguiu diferenciar o mérito dos desempenhos. Aliás, o modelo parece ter tido um efeito contrário, já que "veio piorar o ambiente que se vive nas escolas" (D5) e segundo outro diretor "o que aconteceu até hoje não devia ter acontecido, foi prejudicial para os professores, foi desestabilizador para o processo de trabalho, para o processo de ensino aprendizagem também" (D7).

Vários foram os problemas identificados. Desde logo, a componente exageradamente burocrática associada à difícil operacionalização do modelo foram aspetos alvo de críticas negativas muito fortes e transversais a todos os inquiridos. A dificuldade com que as escolas se debateram para o pôr em prática ficou patente nas seguintes intervenções: "O mais difícil foi compreender a aplicação do modelo. $\mathrm{O}$ legislador não conseguiu prever a sua aplicação" (D8); "foi operacionalizar todo o sistema de avaliação! É uma coisa difícil e quase impossível de se fazer. Nós tomámos uma posição que foi escrever à DGRHE a dizer que éramos incompetentes..." (D5).

A questão relativa aos avaliadores foi outra das principais fragilidades causadora, em grande parte, do insucesso do modelo em estudo. Por um lado, a existência de vários relatores em cada escola tornou complexa a harmonização das classificações, já que cada relator fez uma interpretação subjetiva dos padrões e descritores de desempenho. Por outro, a carência 
de formação especializada em avaliação de desempenho tornou-se o maior constrangimento ao desempenho dos avaliadores, nos quais se inclui o diretor, para além de ter tido implicações na legitimidade e credibilidade dos avaliadores junto dos avaliados:

Foi a falta de formação generalizada em avaliação de desempenho, tivemos que aplicar um modelo, construindo documentos de registo e encontrando soluções várias sem qualquer preparação para tal. Avaliar não é um processo fácil e pacífico e fazê-lo sem as ferramentas adequadas torna-se uma tarefa pouco séria e consistente (D10).

Deste constrangimento, decorreu um outro, o da credibilidade dos avaliadores, como se depreende da seguinte opinião: "Não tendo formação, não tinham credibilidade perante os colegas" (D8). A falta de formação em avaliação de desempenho parece ser transversal a todas as escolas, sendo um constrangimento igualmente identificado em estudos anteriores (Cardoso, 2012; Mota, 2009; Reis, 2011; Tarrinha, 2010).

A avaliação por pares, aliada às medidas excecionais implementadas para colmatar a insuficiência de avaliadores foram outros dos aspetos negativos, na medida em que "as soluções encontradas fragilizaram o próprio modelo" (D10) e este "corrompeu-se a si próprio" (D11). Este é um problema diretamente associado ao constrangimento que decorre das relações de proximidade estabelecidas entre avaliadores e avaliados já anteriormente identificado pelos diretores. Mesmo os diretores defensores da avaliação por pares admitem que as relações de amizade e de trabalho conjunto constituem uma dificuldade acrescida, atribuindo uma forte carga emotiva ao processo, tal como testemunhado pelas intervenções: "Nós estamos a trabalhar os dois e eu sou teu avaliador, é uma chatice, é uma chatice. Nós temos uma relação [...] há ali um mal-estar" (D9).

A maioria dos participantes declarou que o modelo em estudo não conseguiu diferenciar o mérito por essa diferenciação estar dependente de duas aulas observadas e não ser garantido que, o que nelas se observa, é o reflexo do dia-a-dia do professor, pois as aulas são meticulosamente preparadas para agradar a quem observa e, consequentemente, serem bem avaliadas: "Eu acho que são poucas aulas [...] as coisas podem correr muito bem, as pessoas têm a aula muito bem preparada e nós gostarmos muito e aquilo ser um teatro, ou pelo contrário" (D9). E ainda, porque muitos docentes, apesar de terem sido sujeitos a observação de aulas, não foram avaliados na componente científica, em virtude de os avaliadores não serem do seu grupo de recrutamento: "Quando a avaliação do domínio 
científico e didático pode ser dispensada, em função do avaliador que se conseguiu arranjar, tudo é posto em causa" (D10).

Por outro lado, nem todos os professores requereram a observação de aulas, o que significa que não estava em causa o universo dos docentes, mas um grupo restrito que viu assim alargada a probabilidade de ver o seu desempenho superiormente classificado, facto que levou um diretor a afirmar que quem requereu observação de aulas "aproveita a oportunidade! Isto é grave. É a completa subversão de todo o sistema!" (D11).

Neste enquadramento, ressaltam duas opiniões contrárias que lembraram que dentro do grupo dos professores com observação de aulas, houve lugar à diferenciação do mérito, o que dá sentido à firmação de que "aqueles que tiveram muito bom, com certeza cumpriram alguns requisitos melhor que outros" (D1) e justifica o preenchimento das quotas em inúmeras escolas. Porém, mesmo estes diretores reconhecem que o modelo ao permitir classificações de mérito sem que isso implique a apreciação da competência científica e didática, não mede da melhor forma os desempenhos, pelo que a diferenciação fica, naturalmente, fragilizada.

Quando questionados sobre as potencialidades do modelo, o sentir geral foi "tenho dificuldades em encontrar potencialidades" (D10). Apenas um diretor apontou como positiva a elaboração dos perfis de desempenho a nível nacional e outro, a avaliação por pares dentro do mesmo grupo de recrutamento: "Uma potencialidade deste modelo foi, quanto a mim, aquela questão da definição dos padrões de desempenho... O facto de teres um padrão de desempenho igual para todo o país, para todas as escolas criou alguma uniformidade" (D1); "Tem uma potencialidade que, na minha perspetiva, acho que é fundamental e eu acho que não se deve perder, a avaliação por pares! Ao contrário do que muitos pensam, eu penso que é uma potencialidade" (D7).

\section{CONCLUSÕES}

Do estudo empírico concluiu-se que é amplamente consensual entre os diretores que a avaliação de desempenho é importante para o desenvolvimento profissional dos professores e este, por sua vez, é importante para a qualidade do processo ensino-aprendizagem. Concluiuse também que o modelo em estudo não foi um modelo bem-sucedido, na perspetiva dos diretores, não tendo atingido nenhum dos objetivos elencados no D.R. n. ${ }^{\circ}$ 2/2010. Tal constatação decorre, sobretudo, da complexidade que o modelo encerra em si próprio, dos critérios administrativos que regularam a nomeação dos avaliadores, bem como da 
falta de formação em avaliação de desempenho transversal aos vários intervenientes.

Uns meses após a realização das entrevistas foi publicado o D.R. n. ${ }^{\circ}$ 26/2012, de 21 de fevereiro, que estabeleceu um novo modelo de avaliação de desempenho docente. Neste seguimento, fez-se uma análise do mesmo e constata-se que vem ao encontro das expetativas dos diretores envolvidos no estudo empírico, nos seguintes aspetos:

- Define claramente a relevância da dimensão cientifico-pedagógica que conta com uma ponderação de $60 \%$, na classificação sendo que, caso haja lugar à avaliação externa (observação de aulas), esta representa $70 \%$ dos anteriores $60 \%$. Para a centralidade das práticas letivas, concorre ainda a obrigatoriedade de observação de aulas para a atribuição da menção de excelente.

- A avaliação passa a ter uma componente interna e externa, correspondendo a cada uma delas um avaliador, o que significa que a responsabilidade da avaliação é partilhada por um avaliador interno e externo;

- Os avaliadores pertencem obrigatoriamente ao grupo de recrutamento do avaliado;

- Os ciclos avaliativos são coincidentes com os escalões da carreira.

A estas opções não é alheia a vontade de fazer associar a qualidade das práticas docentes aos resultados dos alunos, numa lógica de prestação de contas e responsabilização pelos processos e pelos resultados. Por seu turno, também esta responsabilização implica o reconhecimento do mérito do professor e este ser cada vez mais associado à gestão da carreira.

Contudo, nem todas as recomendações dos diretores colheram eco no D.R. n. ${ }^{\circ}$ 26/2012, de 21 de fevereiro. De entre estas, chamamos a atenção para a questão dos avaliadores. Continua a não ser obrigatório que sejam portadores de formação especializada em avaliação de desempenho. Para o exercício da função, basta-lhes possuírem experiência profissional em supervisão, pelo que para o cumprimento deste requisito verificou-se ser suficiente terem sido relatores no ciclo avaliativo 2009/2011. Acresce que os avaliadores internos são os coordenadores de departamento, podendo delegar a responsabilidade da avaliação, em docentes que reúnam os requisitos exigidos aos avaliadores externos. Tal não sendo possível, manter-se-á o coordenador como avaliador interno. Assim, não há, na prática, obrigatoriedade de o avaliador e avaliado pertencerem ao mesmo grupo de recrutamento. É provável que esta questão se deva ao facto de ser reduzido o número de professores com formação especializada em 
avaliação de desempenho, o que reflete um fraco nível de capacitação para o exercício das funções de avaliador.

Posto isto, cumpre-nos referir que uma possível limitação deste estudo diz respeito ao facto de até ao final do ciclo 2009/2011, nenhum modelo avaliativo recorreu a avaliadores externos. Neste contexto, julgamos pertinente, analisar o posicionamento da classe docente face aos avaliadores externos, pela primeira vez em funções na sequência do modelo implementado pelo D.R. n. ${ }^{\circ}$ 26/2012, de 21 de fevereiro.

\section{REFERÊNCIAS}

Abrantes, P. (2010). Políticas de avaliação e avaliação das políticas: o caso português no contexto ibero-americano. Revista Iberoamericana de Educación, 53, 25-42.

Alves, M., \& Machado, E. (2008). Para uma perspectiva dialógica de avaliação de escola. In M. Alves, E. Machado (Eds.). Avaliação com sentido(s): Contributos e questionamentos (pp. 97-108). Santo Tirso: De Facto Editores.

Assaél, J., \& Pavez, J. (2008). La construcción e implementación del Sistema de Evaluatión del Desempeño Docente Chileno. Revista Iberoamericana de Evaluatión Educativa, 1 (2), 41-55.

Avalos, B. (2010). O sistema chileno de avaliação de desempenho docente. In M. Flores (Ed.), A avaliação de professores numa perspectiva internacional - Sentidos e Implicações (pp. 45-63). Porto: Areal Editores.

Azevedo, J. (2002). O fim de um ciclo? A educação em Portugal no início do século XXI. Porto: Edições Asa.

Bardin, L. (2008). Análise de conteúdo. Lisboa: Edições 70.

Bodgan, R., \& Bicklen, S. (1994). Investigação qualitativa em educação. Porto: Porto Editora.

Bolívar, A. (2007). Um olhar actual sobre a mudança educativa: onde situar os esforços da melhoria? In C. Leite, A. Lopes (Eds.), Escola, currículo e formação de identidades: Estudos de investigação (pp. 13-50). Porto: Edições Asa.

Caetano, A. (2008). Avaliação de Desempenho - O essencial que avaliadores e avaliados precisam de saber. Lisboa: Livros Horizonte.

Campos, M. (2005). A avaliação e gestão do desempenho dos professores. Tese de Doutoramento. Faculdade de Ciências Humanas e Sociais, Universidade do Algarve. 
Cardoso, A. (2012). A avaliação do desempenho docente e o professor titular: Um estudo de caso numa perspetiva organizacional. Tese de Doutoramento. Departamento de Educação, Universidade de Aveiro.

Carmo, H., \& Ferreira, M. (2008). Metodologia da Investigação - Guia para Auto-aprendizagem ( $2^{\mathrm{a}}$ edição). Lisboa: Universidade Aberta.

Chiavenato, I. (1990). Recursos Humanos. S. Paulo: Editora Atlas.

Clímaco, M. (2007). Comentário à intervenção de Gérard Figari. In C. Ramos (Ed.), Avaliação de professores: Visões e realidades. Actas da Conferência Internacional (pp. 27-30). Lisboa: Conselho Científico para a Avaliação de Professores.

CONSELHO CIENTÍFICO para a AVALIAÇÃO de PROFESSORES (2009). Recomendação n. ${ }^{\circ}$ 5/CCAP/2009, de 8 de Junho. Regime de avaliação de avaliação de desempenho docente. Contributos para a tomada de decisão.

Costa, E. (2007). Contributo para uma análise cognitiva da política de avaliação de professores. Sísifo. Revista de Ciências da Educação, 4, 49-58.

Cruz, I. (2011). Potenciar as práticas de observação de aulas - supervisão e colaboração. In E. Machado, M. Alves, F. Gonçalves (Eds.), Observar e avaliar as práticas docentes (pp. 81-94). Santo Tirso: De Facto Editores.

Cunha, A. (2008). Ser professor. Bases de uma sistematização teórica. Braga: Casa do Professor.

Danielson, C. (2010). Melhorar a prática profissional. Um quadro de referência para a docência. Lisboa: Ministério da Educação.

Day, C. (2010). Formas de avaliação docente em Inglaterra: Profissionalismo e Performatividade. In M. Flores (Ed.), A avaliação de professores numa perspectiva internacional: Sentidos $e$ implicações (pp. 141-161). Porto: Areal Editores.

De Ketele, J. (2010). A avaliação do desenvolvimento profissional dos professores: Postura de controlo ou postura de reconhecimento? In M. Alves, E. Machado (Eds.), O pólo de excelência - Caminhos para a avaliação do desempenho docente (pp. 13-30). Porto: Areal Editores.

Díaz, A. (2003). Avaliação da qualidade das escolas. Porto. Edições ASA.

Esteves, M. (2006). Análise de conteúdo. In J. Lima, J. Pacheco (Eds.), Fazer investigação. Contributos para a elaboração de dissertações e teses (pp. 105-126). Porto: Porto Editora. 
Fernandes, D. (2009). Para uma avaliação de professores com sentido social e cultural. ELO, 16, 19-23.

Ferreira, C. (2006). Avaliação de desempenho docente: expectativas dos professores. Dissertação de mestrado. Universidade Portucalense.

Figari, G. (2007). A avaliação dos professores Entre o controle e o desenvolvimento. In C. Ramos (Ed.), Avaliação de professores: Visões e realidades. Actas da Conferência Internacional (pp. 17-26), Lisboa: Conselho Científico para a Avaliação de Professores.

Flores, M. (2009). Da avaliação de professores: Reflexões sobre o caso português. Revista Iberoamericana de Evaluación Educativa, 2 (1), 239-256.

Flores, M. (Eds.) (2010). A avaliação de professores numa perspectiva internacional: Sentidos e Implicações. Porto: Areal Editores.

Flores, M., Alves, M., \& Machado, E. (Eds.) (2011). Quanto vale o que fazemos? Práticas de Avaliação de Desempenho. Santo Tirso: De Facto Editores.

Formosinho, J., Machado, J., \& Formosinho, J. (Eds.) (2010). Formação, desempenho e avaliação de professores. Mangualde: Edições Pedagogo.

Góis, E., \& Gonçalves, C. (2005). Melhorar as escolas - Práticas eficazes. Porto: Edições Asa.

Goldrick, L. (2002). Improving Teacher Evaluation to Improve Teaching Quality. National Governors Association.

Lima, J. (2002). As culturas colaborativas nas escolas. Estruturas, processos e conteúdos. Porto: Porto Editora.

Lima, M., \& Moreira, J. (2011). Concepções sobre avaliação e o (Plano de) Desenvolvimento Profissional. In M. Alves, M. Flores, E. Machado (Eds.), Quanto vale o que fazemos? Práticas de avaliação de desempenho (pp. 123-151). Santo Tirso: De Facto Editores.

Machado, E., Alves, M., \& Gonçalves, F. (2011). Apresentação da obra. In E. Machado, M. Alves, F. Gonçalves (Eds.), Observar e avaliar as práticas docentes (pp. 7-16). Santo Tirso: De facto Editores.

Machado, J., \& Formosinho, J. (2009). Desempenho, mérito e desenvolvimento - Para uma avaliação mais profissional dos professores. $E L O, 16,287-306$.

Máximo-Esteves, L. (2008). Visão panorâmica da investigação-ação. Porto: Porto Editora.

Mestre, M. (2002). Avaliação num contexto de supervisão. Lisboa: Instituto de Inovação e Desenvolvimento Educacional.

Moreira, M. (2009). Supervisão interpares, avaliação e autonomia profissional. ELO, 16, 37-41. 
Moreira, M. (2011). O lugar da observação na avaliação docente: O que vale o que observamos? In M. Alves, M. Flores, E. Machado (Eds.), Quanto vale o que fazemos? Práticas de avaliação de desempenho (pp. 17-38). Santo Tirso: De Facto Editores.

Morgado, J. (2005). Currículo e profissionalidade docente. Porto: Porto Editora.

Mota, V. (2009). O novo modelo de avaliação do desempenho docente: formação e perceção dos agentes avaliativos. Dissertação de mestrado. Faculdade de Psicologia e Ciências da Educação, Universidade de Coimbra.

Murillo, J. (2007). Uma visão panorâmica da avaliação de desempenho docente na Europa e na América. In C. Ramos (Ed.), Avaliação de professores: Visões e realidades. Actas da Conferência Internacional (pp. 33-42), Lisboa: Conselho Científico para a Avaliação de Professores.

Nevo, D. (2005). The conceptualization of educacional evaluation: an analytical review of the literature. In E. House (Ed.), New Directions in educational evaluation (pp. 15-29). Oxon: Routledger Falmer.

OCDE (2009). Evaluation and Rewarding the Quality of Teachers: International Pratices.

Peterson, K. (1997). Assesoramiento y evaluación para el professorado principiante. In J. Millan, L. Darling-Hammond (Eds.), Manual para la evaluación del professorado (pp. 147-164). Madrid: Editorial La Muralla.

Posada, J. (2009). La Evaluatión de los Professores: Trivializar la evaluatión o evaluar lo trivial? In J. Ruivo, A. Trigueiros (Eds.), Avaliação de desempenho de professores (pp. 77-89). RVJ Editores.

Ramos, C. (2007). A importância da avaliação do desempenho de professores. In C. Ramos (Ed.), Avaliação de professores: Visões e realidades. Actas da Conferência Internacional (pp. 11-16), Lisboa: Conselho Científico para a Avaliação de Professores.

Reis, P. (2011). Observação de aulas e avaliação de desempenho docente. Cadernos do CCAP-2.

Roldão, M. (1999). Os professores e a gestão do currículo perspectivas e práticas em análise. Porto: Porto Editora.

Roldão, M. (2003). Gestão do currículo e avaliação de competências. As questões dos professores. Lisboa: Editorial Presença.

Roman, M., \& Murillo, F. (2008). La evaluación del desempeño docente: objeto de disputa y fuente de oportunidades en el campo educativo. Revista Iberoamericana de Evaluación Educativa, 1 (2), 1-6. 
Ruivo, J., \& Trigueiros, A. (Eds.) (2009). Avaliação de desempenho de professores. Braga: RVJ Editores.

Scriven, M. (1997). Truth and objectivity in evaluation. In E. Chelimsky, W. Shadish (Eds.), Evaluation for the 21st Century: A Handbook (pp. 477-500). Thousand Hoaks: Sage Publications.

Silva, A. (2011). Sob o olhar do outro: desafios éticos na avaliação e na observação do desempenho docente. In E. Machado, M. Alves, F. Gonçalves (Eds.), Observar e avaliar as práticas docentes (pp. 19127). Santo Tirso: De Facto Editores.

Simões, G. (2000). A avaliação de desempenho docente. Lisboa: Texto Editora.

Stronge, J. (2010). O que funciona, de facto, na avaliação dos professores: breves considerações. In M. Flores (Ed.), A avaliação de professores numa perspectiva internacional: Sentidos e implicações (pp. 22-43). Porto: Areal Editores.

Tardif, L., \& Faucher, C. (2010). Um conjunto de balizas para avaliação da profissionalidade dos professores. In M. Alves, E. Machado (Eds.), O pólo da excelência: Caminhos para a avaliação do desempenho docente (pp. 32-53). Porto: Areal Editores.

Tarrinha, A. (2010). Observação do ensino no âmbito da avaliação de desempenho docente. Dissertação de mestrado. Faculdade de Psicologia e Ciências da Educação, Universidade de Coimbra.

Tuckman, B. (2000). Manual de investigação em educação. Lisboa: Fundação Calouste Gulbenkian.

Vicente, N. (2004). Guia do gestor escolar: Da escola de qualidade mínima garantida à escola com garantia de qualidade. Porto: Edições Asa. 